\title{
High efficiency LOW AM/PM 6W C-band MMIC power amplifier for a space radar program
}

\author{
Y. Butel, T. Adam, B. Cogo, M. Soulard \\ Alcatel Space Industries - 26 AV. JF Champollion -BP 1187 - 31037 Toulouse -France \\ yves.butel@space.alcatel.fr
}

\begin{abstract}
This paper describes the design of a compact C-band MMIC power amplifier. Intensive non-linear and electro-magnetic simulations with accurate table-based models allowed the chips to achieve very good performance. A linear gain of 28 $\mathrm{dB}$, an output power greater than $6 \mathrm{~W}$ with $50 \%$ of power added efficiency and $3 \% \mathrm{~dB}$ of $\mathrm{AM} / \mathrm{PM}$ conversion at $2.5 \mathrm{~dB}$ gain compression have been measured over production at ambient temperature in the useful bandwidth.
\end{abstract}

\section{INTRODUCTION}

New developments of active antennas for satellite synthetic aperture radar (SAR) applications require high output power and high power added efficiency amplifiers. Due to the large amount of $\mathrm{T} / \mathrm{R}$ modules having to be integrated, a full MMIC output power amplifier is a very interesting solution in order to reduce the size and the weight of the equipment. Then, improving the MMIC amplifier PAE state of art is a mandatory challenge in order to compete with hybrid solutions because payload consumption is a critical parameter. In the same time, SAR applications require two other important characteristics : to insure MMIC unconditional stability under pulsed drain bias conditions and to reduce AM/PM conversion in order to reach phase stability and linearity requirements.

\section{MMIC DESIGN}

\section{Devices modeling :}

The amplifier has been designed using TriquintTexas $0.25 \mu \mathrm{m}$ power P-HEMT process.

A full pulsed $\mathrm{S}$-parameter characterization (from DC to $40 \mathrm{GHz}$ ) of transistors issued from previous runs [1] was performed to extract the linear and non-linear models. A customized table-based model [2] including the main current source $\mathrm{I}_{\mathrm{DS}}\left(\mathrm{V}_{\mathrm{DS}}, \mathrm{V}_{\mathrm{GS}}\right)$ and the capacitance's $\mathrm{C}_{\mathrm{GS}}\left(\mathrm{V}_{\mathrm{DS}}, \mathrm{V}_{\mathrm{GS}}\right)$ and $\mathrm{C}_{\mathrm{GD}}\left(\mathrm{V}_{\mathrm{DS}}, \mathrm{V}_{\mathrm{GS}}\right)$ has been computed to insure the accuracy of simulations even under deep compression levels.

\section{Circuit description :}

As shown on figure 1 , this 2 stages amplifier is constituted of a $4 \times 1.5 \mathrm{~mm}$ stage driving a $8 \times 2 \mathrm{~mm}$ power stage. They are both biased in deep AB class $\left(\mathrm{I}_{\mathrm{MAX}} / 10\right)$ in order to maximize PAE. A 2.7:1 ratio in gate developments between the two stages guaranties the linearity of the $1^{\text {st }}$ stage within the deep global compression level of the complete circuit and makes the inter-stage power matching easier. The final dimension of the chip is $5.2 \times 3.5 \mathrm{~mm}^{2}$.

The output power and the power added efficiency have been optimized using load-pull and source-pull simulations. The inter-stage was also optimized considering losses, gain flatness and power matching of the first stage.

The output combining network and the inter-stage have been simulated using HP MOMENTUM. Due to the relatively important thickness of lines, the quasi-3D method has to be used to obtain accurate results [3], [4].

The stability of the circuit has been intensively studied using different methods. First, the conditions on Rollet factors of each individual stage has been verified (e.g. $\mathrm{K}>1$ and $\mathrm{B} 1>0$ vs. process variations). Then the Nyquist Determinant Function (NDF) [5] analysis versus drain voltage has been performed and the different odd mode stabilizing elements (gate to gate and drain to drain) have been optimized. This insures safe operating conditions during drain bias pulse from $0 \mathrm{~V}$ to $\mathrm{V}_{\mathrm{D}} \max$.

The circuit has been optimized between $5.0 \mathrm{GHz}$ and $5.8 \mathrm{GHz}$ to insure margins versus the $100 \mathrm{MHz}$ application bandwidth.

The simulated linear performance of the circuit are presented in figures 2 and 3. The linear gain is greater than $28 \mathrm{~dB}$ and the return losses are better than $-15 \mathrm{~dB}$ in the optimized frequency band $(5-5.8 \mathrm{GHz})$. 


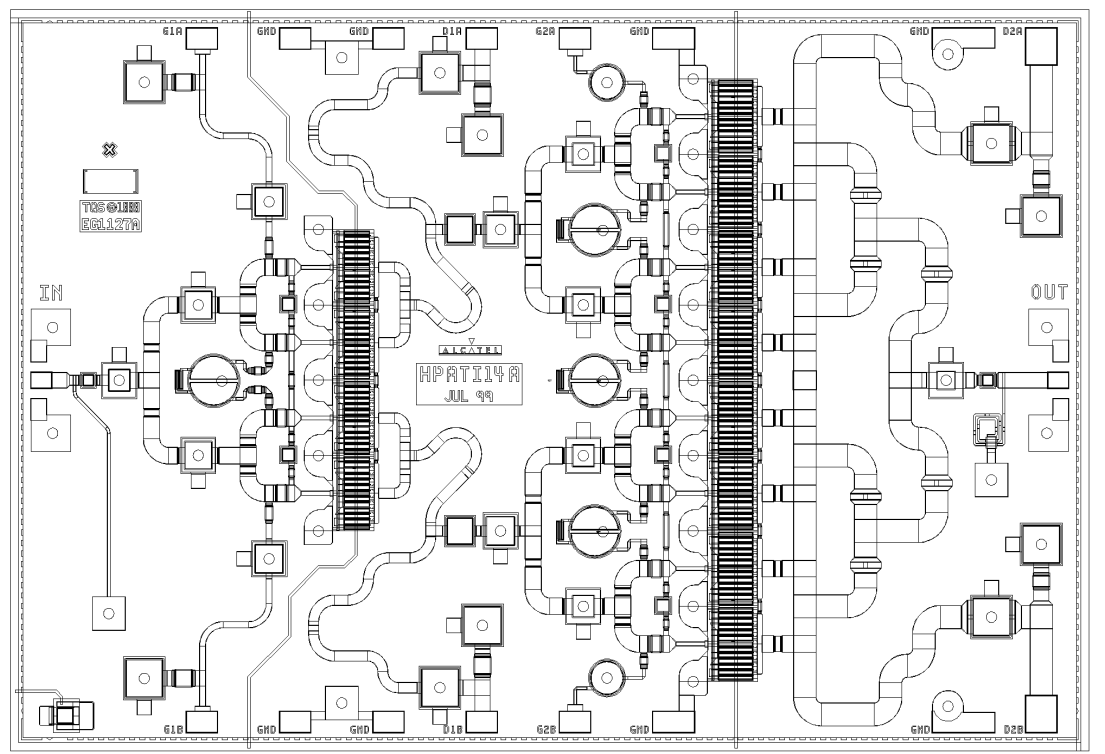

Fig. 1 : Layout of the chip $\left(5.2 \times 3.5 \mathrm{~mm}^{2}\right)$

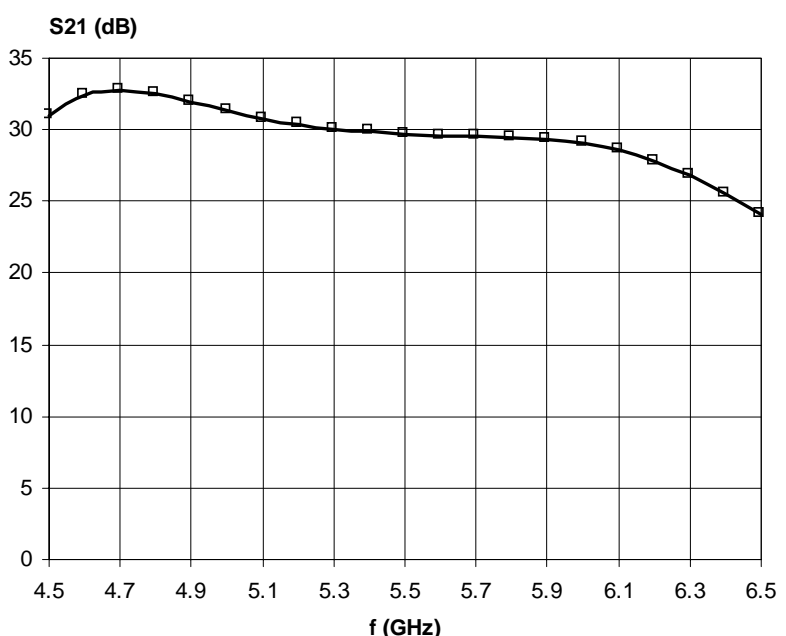

Fig. 2 : simulated $\mathrm{S} 21(\mathrm{~dB})$ at $\mathrm{V}_{\mathrm{D}}=8 \mathrm{~V}$

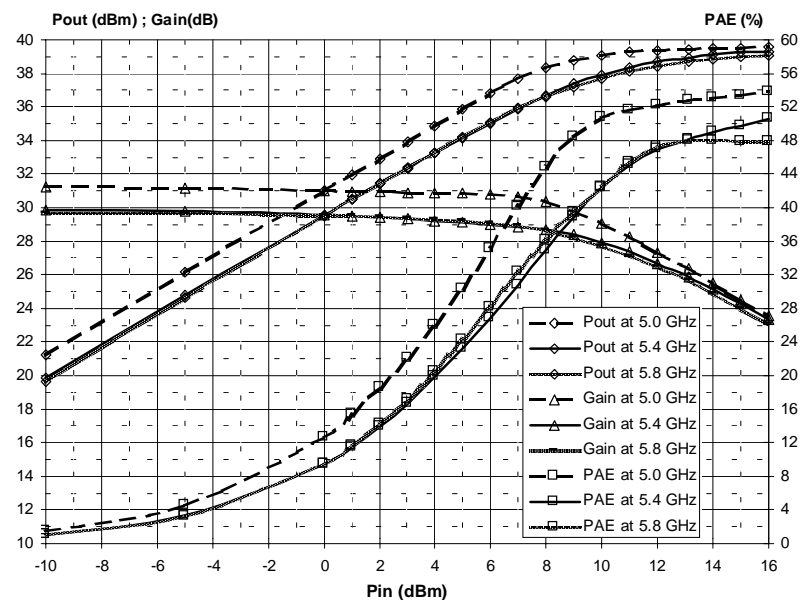

Fig. 4 : Simulated Gain, Output Power and PAE

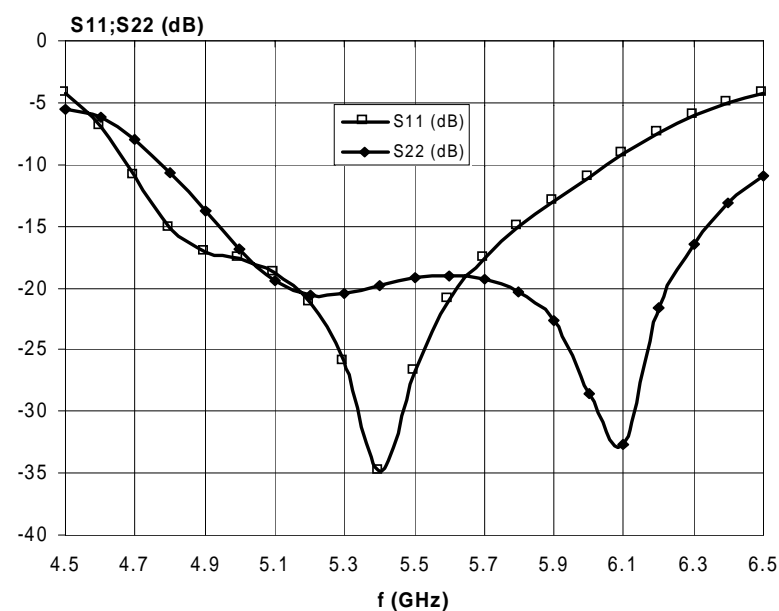

Fig. 3 : simulated $\mathrm{S} 11$ and $\mathrm{S} 22(\mathrm{~dB})$ at $\mathrm{V}_{\mathrm{D}}=8 \mathrm{~V}$

The simulated non-linear performance of the amplifier are presented in figure 4. At $2.5 \mathrm{~dB}$ gain compression, the output power is greater than $38 \mathrm{dBm}$ and the power added efficiency is better than $44 \%$ over the $5.0-5.8 \mathrm{GHz}$ frequency band.

\section{MMIC MEASUREMENTS}

Two types of measurements have been performed on this chip: On-wafer measurements and packaged MMIC measurements. RF probe measurements at Wafer level are realized on each MMIC under reduced bias conditions in order to avoid thermal problems. These measurements give a good assessment of the relative MMIC performance, but do not accurately 
provide the values of the absolute performance. In order to accurately measure important parameters such as linear gain or output power, some representative dies of the whole lot, located at extreme and mean positions into the dispersion charts, have been fully characterized while mounted into a specific package providing thermal control and good RF interconnection accesses as shown on figure 5 .

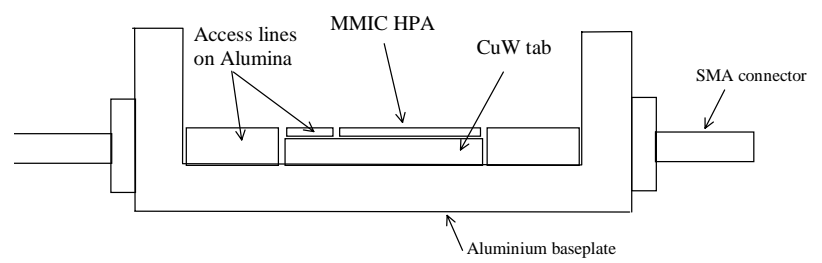

Fig. 5 : test fixture of the HPA

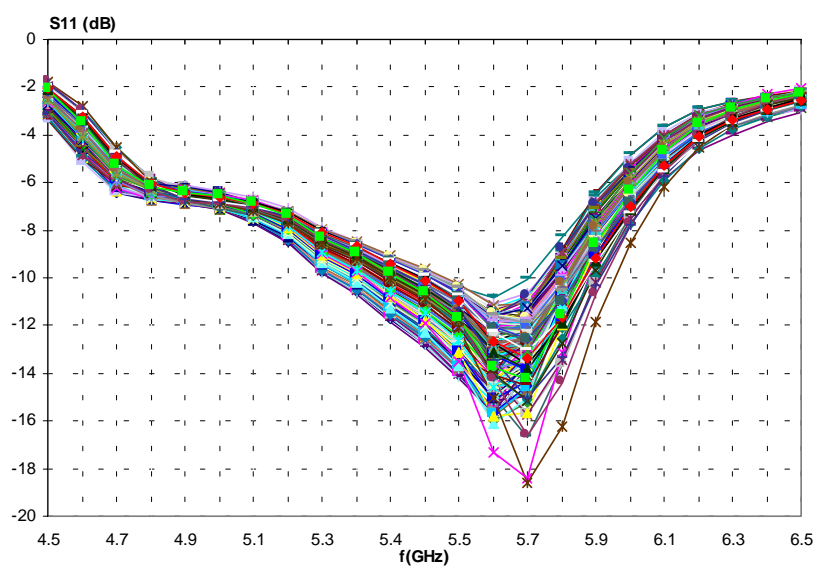

Fig. 6 : measured $\mathrm{S} 11(\mathrm{~dB})$ at $\mathrm{V}_{\mathrm{D}}=6 \mathrm{~V}$ ambient temperature over production

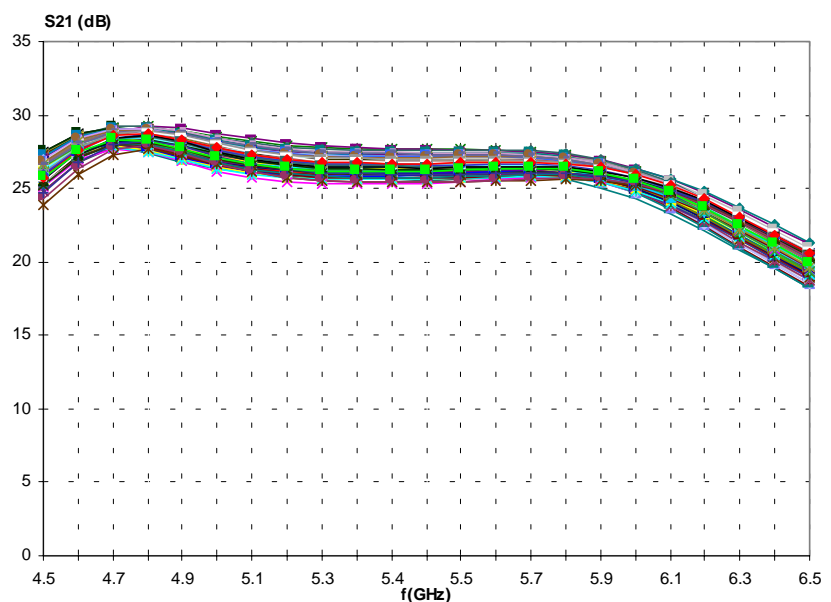

Fig. 8 : measured $S 21(\mathrm{~dB})$ at $\mathrm{V}_{\mathrm{D}}=6 \mathrm{~V}$ ambient temperature over production

\section{On Wafer measurement}

RF probe measurements including linear and non linear characterization have been performed on every chip at $\mathrm{Vd}=6 \mathrm{~V}$.

Figures 6,7 and 8 exhibit the S-parameter measurements :

- Linear gain spread over production remains within $2 \mathrm{~dB}$ between $5.0-5.8 \mathrm{GHz}$

- Input reflection losses remains lower than $-6.5 \mathrm{~dB}$ within $5.0-5.8 \mathrm{GHz}$

- Output reflection losses remains lower than $-11 \mathrm{~dB}$ within $5.0-5.8 \mathrm{GHz}$

Figure 9 shows an output power spread over production of about $1.2 \mathrm{~dB}$ at fixed input power.

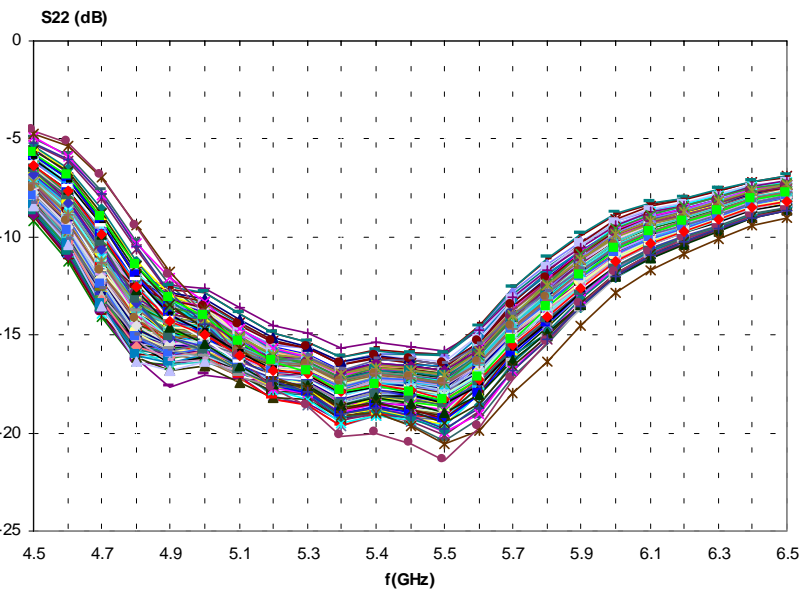

Fig. 7 : measured $\mathrm{S} 22(\mathrm{~dB})$ at $\mathrm{V}_{\mathrm{D}}=6 \mathrm{~V}$ ambient temperature over production

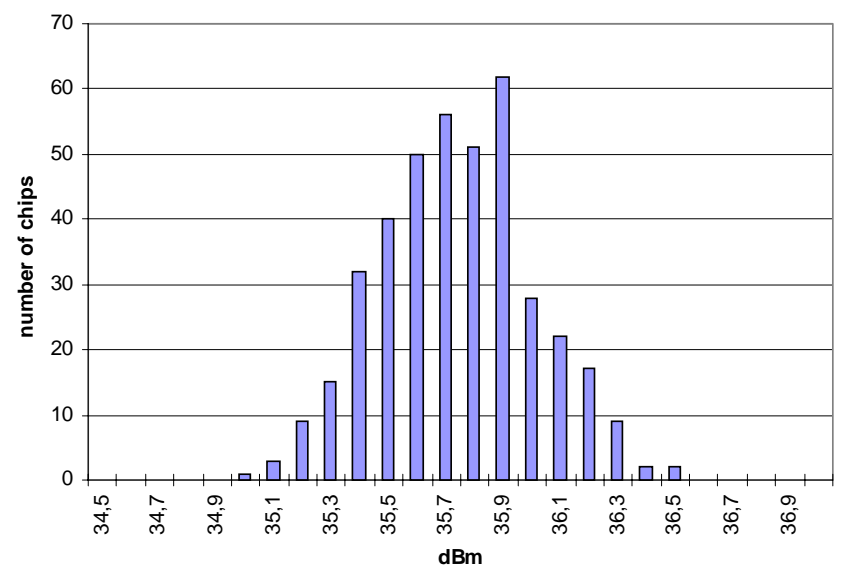

Fig. 9 : Output power spread at $\mathrm{V}_{\mathrm{D}}=6 \mathrm{~V}$ ambient temperature over production 


\section{Packaged MMIC measurement in pulsed mode}

The measurements presented figure 10 and 11 have been performed on a die featuring average performances, i.e. delivering a mean output power over production. Drain voltage pulse duration is 40us for a duty cycle of about $10 \%$.

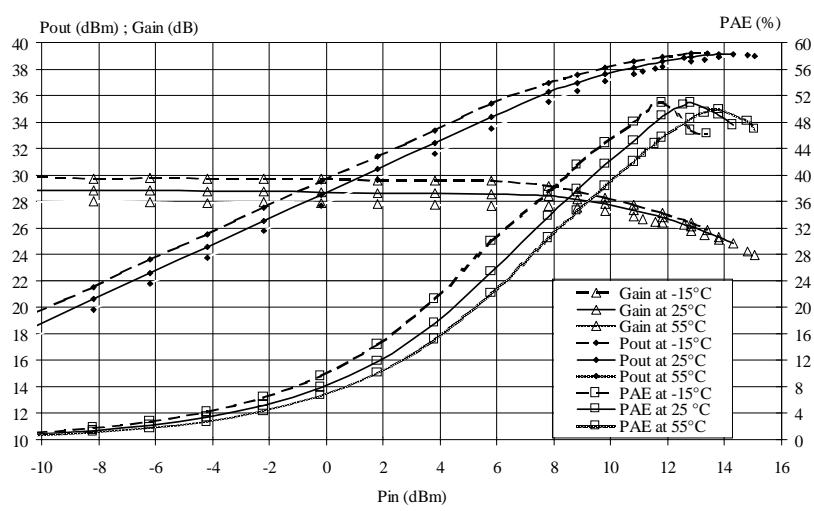

Fig. 10 : Pout, Gain and PAE versus Pin $3 \mathrm{~T}\left(-15^{\circ} \mathrm{C}, 25^{\circ} \mathrm{C}, 55^{\circ} \mathrm{C}\right.$ at bottom chip level $)$

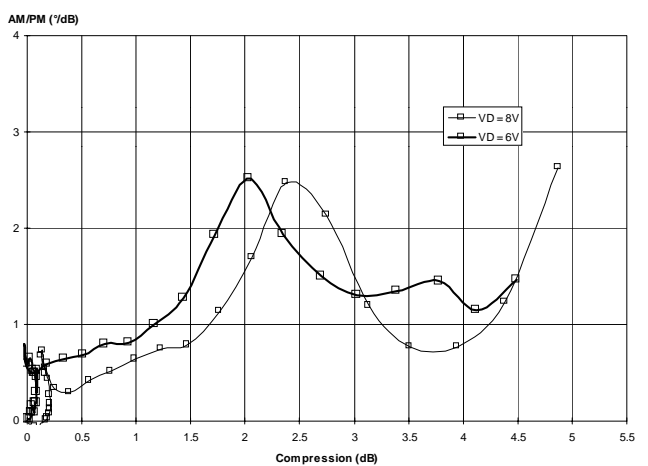

Fig. 11 : AM/PM versus compression state $\mathrm{T}=-15^{\circ} \mathrm{C}$ (bottom chip level)

Output power, gain and PAE versus input power are shown on the figure 10 for 3 temperatures. Worst case output power is about $38.7 \mathrm{dBm}$ at $2.5 \mathrm{~dB}$ compression with a PAE higher than $50 \%$. Linear gain remains higher than $27.9 \mathrm{~dB}$ at $55^{\circ} \mathrm{C}$ bottom chip temperature.

A very good agreement can be found between the non linear simulations and the pulsed measurements.

The figure 11 exhibits an AM/PM characteristic lower than $3 \% \mathrm{~dB}$ at $5.4 \mathrm{GHz}$ till $5 \mathrm{~dB}$ compression in the worst case temperature conditions $\left(-15^{\circ} \mathrm{C}\right.$ at bottom chip level).

\section{IV.CONCLUSION}

The design and measurement of a high power MMIC C-band amplifier dedicated to space synthetic aperture radar applications has been presented. Power P-HEMT technology permits to achieve very high overall performance particularly on important criteria such as AM/PM conversion and power added efficiency. Due to their small size and high power density compared to hybrids, MMIC power amplifiers are a great prospect technology for satellite applications.

\section{ACKNOWLEDGMENTS}

Authors would like to thank the staff of Triquint Semiconductors Texas for the foundry service and for the wafer measurements support, H. YAHI, RF technician at ASPI for his rigor and tenacity and O. PERRIN from Detexis Thomson-CSF for all the fruitful discussions about $\mathrm{T} / \mathrm{R}$ module requirements

\section{VI.REFERENCES}

[1] L. LOVAL , A. DARBANDI, H. BURET, M. SOULARD, F. MICHARD : "8 W C-band MMIC amplifier for space applications" , IEEE GaAs IC Symposium - OCT 1999 - Monterey California, USA

[2] J.M. COLLANTES, J.J. RAOUX, A. SUAREZ : "New Measurement-Based Technique for RF LDMOS Nonlinear Modeling.", IEEE microwave and guided wave letters, OCT 011998 v 8 n 10

[3] J. DUBOULOY \& al, "Simulation électromagnétique quasi 3D à l'aide d'un logiciel 2,5 D", 3D11, JNM 1997, St Malo

[4] A.M. PEREZ, "Skin effect and thick lines", HP eesof notes, SEP 28, 1998.

[5] S. MONS, M.A. PEREZ, R. QUERE, J. OBREGON "A Unified Approach for the Linear and Nonlinear Stability Analysis of Microwave Circuits Using Commercially Available Tools", . 1999 IEEE MTT-S, vol. 3, pp 993-996. 